\title{
Polymerization of Poly Propylene Oxide
}

\section{Lahouari Mrah*, Rachid Megabar and Mohammed Belbachir}

Laboratory of Polymer Chemistry, Department of Chemistry, Faculty of Science, Université D'Oran, Algeria

We try to identify the relationship structures / properties of the polymer nanocomposites. The addition of nanocomposites quantity of montmorillonite in the matrix poly (propylene oxide) allowed us to highlight the strength properties of the nanocomposites by a non homogeneously dispersed in the PPO matrix.

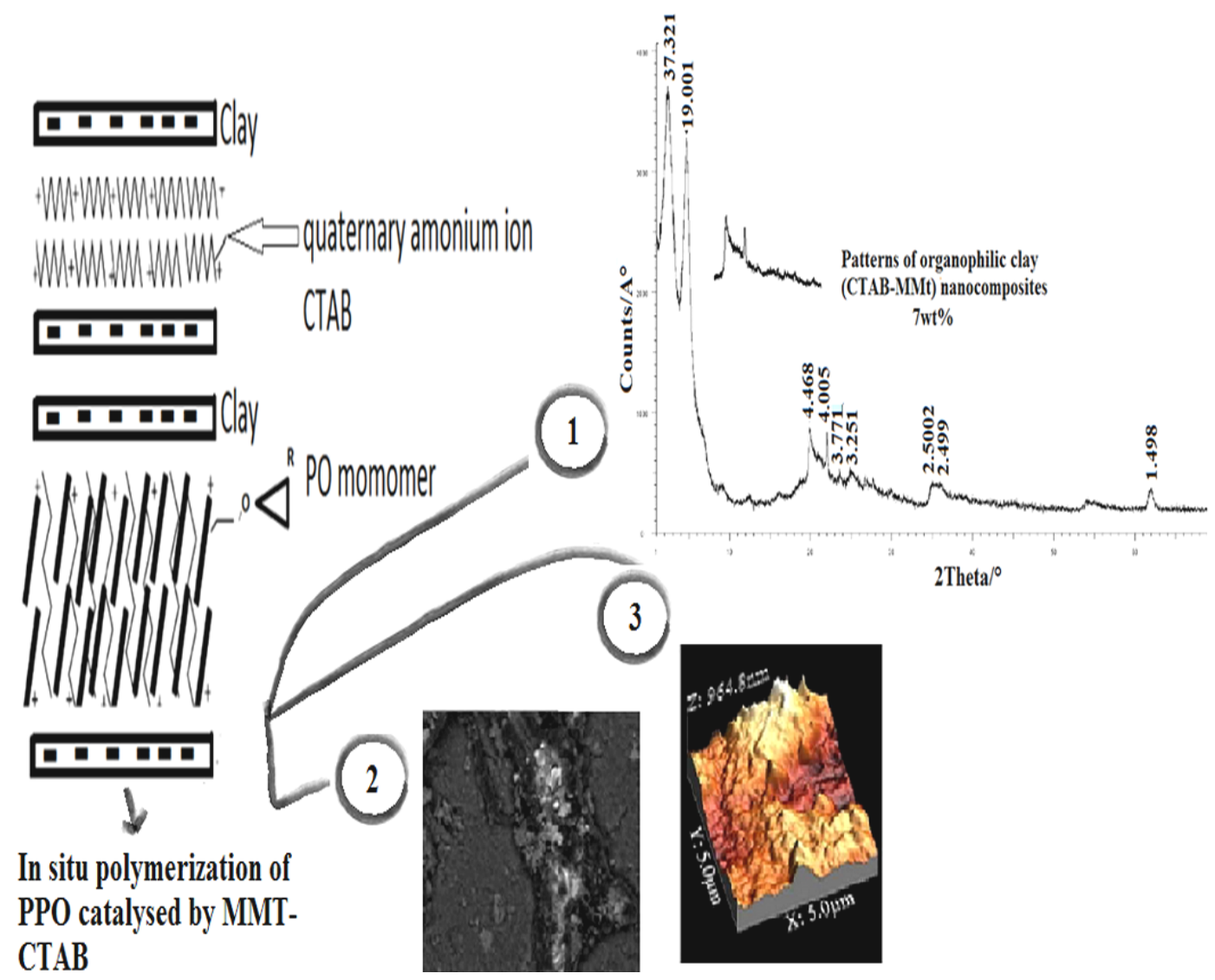

*Corresponding author: Lahouari Mrah, Laboratory of Polymer Chemistry, Department of Chemistry, Faculty of Science, Université D'Oran, BP 152431000 El'Menouer Oran Algeria, Tel: 21341510057; E-mail: Imrah@yahoo.fr

Received January 20, 2015; Accepted January 21, 2015; Published January 30, 2015

Citation: Mrah L, Megabar R, Belbachir M (2015) Polymerization of Poly Propylene Oxide. J Nanomed Nanotechnol 6: I101. doi:10.4172/2157-7439.1000I101

Copyright: (c) 2015 Mrah L, et al. This is an open-access article distributed under the terms of the Creative Commons Attribution License, which permits unrestricted use, distribution, and reproduction in any medium, provided the original author and source are credited. 